University of Nebraska - Lincoln

DigitalCommons@University of Nebraska - Lincoln

Faculty Publications from the Harold W. Manter Laboratory of Parasitology

1995

\title{
Genetic Structure of Midwestern Ascaris suum Populations: A Comparison of Isoenzyme and RAPD Markers
}

\author{
Steven A. Nadler \\ University of California - Davis, sanadler@ucdavis.edu \\ Rachel L. Lindquist \\ Southeast Missouri State University \\ Thomas J. Near \\ Northern Illinois University
}

Follow this and additional works at: https://digitalcommons.unl.edu/parasitologyfacpubs

Part of the Parasitology Commons

\begin{abstract}
Nadler, Steven A.; Lindquist, Rachel L.; and Near, Thomas J., "Genetic Structure of Midwestern Ascaris suum Populations: A Comparison of Isoenzyme and RAPD Markers" (1995). Faculty Publications from the Harold W. Manter Laboratory of Parasitology. 702.

https://digitalcommons.unl.edu/parasitologyfacpubs/702

This Article is brought to you for free and open access by the Parasitology, Harold W. Manter Laboratory of at DigitalCommons@University of Nebraska - Lincoln. It has been accepted for inclusion in Faculty Publications from the Harold W. Manter Laboratory of Parasitology by an authorized administrator of DigitalCommons@University of Nebraska - Lincoln.
\end{abstract}




\title{
GENETIC STRUCTURE OF MIDWESTERN ASCARIS SUUM POPULATIONS: A COMPARISON OF ISOENZYME AND RAPD MARKERS
}

\author{
Steven A. Nadler, Rachel L. Lindquist*, and Thomas J. Near \\ Department of Biological Sciences, Northern Illinois University, DeKalb, Illinois 60115-2861
}

\begin{abstract}
Isoenzyme and random amplified polymorphic DNA (RAPD) markers were used to characterize the genetics of geographic variation among population samples of Ascaris suum from midwestern localities. Independent estimates of fixation indices $\left(F_{S T}\right)$ based on isoenzyme and RAPD markers showed the same general patterns of differentiation and substantial statistical correlation $(r=0.70$ ). Of the total estimated gene diversity, 9.4\% (isoenzyme) and 9.2\% (RAPD) was distributed among infrapopulations. Geographic localities accounted for $7.8 \%$ (isoenzyme) and $6.2 \%$ (RAPD) of the total gene diversity. Only infrapopulations from a single farm were characterized by low fixation indices (isoenzyme and RAPD $F_{S T}<0.05$ ). Isoenzyme and RAPD markers revealed moderate genetic differentiation among infrapopulations and localities, which indicates significant population subdivision among $\boldsymbol{A}$. suum from farms within geographic regions. Departures from random mating were revealed by deficiencies of heterozygotes within infrapopulations and by high positive values of $F_{I S}$ among and between infrapopulations. The average inbreeding $\left(F_{I S}\right)$ coefficient among all infrapopulations was 0.22 . Thus, the genetic composition of these $A$. suum infrapopulations, whether from a general geographic region or a single farm, was not consistent with a model of random recruitment from a larger panmictic pool of parasite life cycle stages.
\end{abstract}

Molecular markers are of great potential utility for revealing intraspecific geographic variation among parasite populations. By studying the genotypes or haplotypes of individuals, nuclear and mitochondrial markers have proved useful for inferring patterns of population genetic structure in some parasitic organisms. For nuclear loci, allelic frequency distributions may be used to estimate genetic differentiation among parasite populations, provided that the alleles are nearly neutral with respect to selection (Lydeard et al., 1989; Nadler, 1990; Nadler et al., 1990; Mulvey et al., 1991; Anderson et al., 1993). Likewise, mitochondrial DNA (mtDNA) haplotypes can be used to describe the distribution of genetic variation within and among parasite populations (Blouin et al., 1992; Tarrant et al., 1992; Anderson et al., 1993; Dame et al., 1993).

Studies of parasite population genetic structure have increased our understanding of basic microevolutionary processes in these organisms and may reveal the likelihood for the spread of resistance genes to anti-parasitic drugs (Anderson et al., 1993; Dame et al., 1993). From an evolutionary perspective, indirect estimates of population subdivision, e.g., $F$-statistics estimated from genetic data, permit characterization of the breeding structure within subpopulations of parasites and reveal the potential for interpopulation differentiation by genetic drift for neutral alleles. Understandably, inferring evolutionary process from the patterns revealed by such statistics may prove complex for many species because the genetic structure of parasite populations will be shaped by properties of the host(s) and parasite (Nadler et al., 1990; Barker et al., 1991; Mulvey et al., 1991; Blouin et al., 1992; Dame et al., 1993). The life history parameters of parasites coupled with host factors such as dispersal, home range, behavior, and demography represent some of the forces that will shape the genetic structure of parasite populations. Studies to date suggest that different species of parasites have population structures that are markedly different. Some taxa show sub-

Received 2 May 1994; revised 12 September 1994; accepted 12 September 1994.

* Department of Biology, Southeast Missouri State University, Cape Girardeau, Missouri 63701. stantial genetic differentiation over small geographic distances (Nadler et al., 1990), and others show minimal differentiation for distances spanning continents (Blouin et al., 1992; Dame et al., 1993).

For many parasite species, the small size of individuals has been an impediment to the acquisition of multilocus genetic data by traditional techniques, e.g., isoenzyme electrophoresis. Thus, for parasites in general and helminths in particular, there is a paucity of studies exploiting the full potential for genetic markers to describe geographic variation among populations. Methods employing the polymerase chain reaction (PCR) can overcome limits based on individual size; however, some of these approaches may impose new methodological (Hadrys et al., 1992) and analytical (Clark and Lonigan, 1993) difficulties. One such method, random amplified polymorphic DNA (RAPD; Williams et al., 1990) is a popular new approach for obtaining genetic data at the intraspecific-level. RAPD genetic markers have also proved useful for a wide variety of molecular ecological applications, including analysis of kinship relationships and paternity (Hadrys, 1991), strain/clone-specific variation (Smith et al., 1992), taxonomic identity (Bandi et al., 1993; Roosien et al., 1993; Gardner et al., 1994), and interspecific hybridization (Arnold et al., 1991). Random Amplified Polymorphic DNAPCR principally amplifies regions of the nuclear genome flanked by inverted sequences complementary to a particular oligonucleotide primer, provided that the primer anneals within the range of efficient amplification for the PCR conditions (Hadrys et al., 1992). Most published studies have documented that RAPD markers are inherited in a Mendelian fashion (Williams et al., 1990; Carlson et al., 1991; Martin et al., 1991; Welsh et al., 1991; Kazan et al., 1993). Herein, we undertake a comparative study of RAPD versus isoenzyme markers in midwestern population samples of Ascaris suum. These isoenzyme data are used to characterize the genetic structure of the populations and as a benchmark for comparing the results obtained using RAPD markers.

\section{MATERIALS AND METHODS}

Ascaris suum adults were collected from the intestines of pigs at a local meat processing plant (FDL, Rochelle, Illinois), washed with $0.85 \%$ 
saline, and maintained for up to $24 \mathrm{hr}$ at $37 \mathrm{C}$ prior to dissection. For each host, entire ascaridoid infrapopulations were collected, an infrapopulation = all parasites of a single species from an individual host (Margolis et al., 1982). Samples of muscle/cuticle and reproductive tissues (testes, uterus, and ovary in the respective sexes) were frozen and stored in cryotubes at $-70 \mathrm{C}$. The 7 hosts sampled included 5 general geographic localities (Burlington [Bur] and Cassopolis [Cas], Michigan; Indianapolis [Indian], Indiana; Fulton [Fult] and Hinckley [Hinck], Illinois). The 2 hosts from Cassopolis came from the same farm (Cas-1, Cas-2); those from Burlington (Bur-1, Bur-2) came from different farms.

Homogenization of tissue samples for protein electrophoresis was performed as described previously (Nadler, 1986). Separate tissue homogenates of muscle and gonad (ovary or testis) were prepared for each individual, and both tissue types were used initially to survey various enzymatic loci. Supernatant fractions of homogenates were absorbed on $4 \times 11$-mm filter paper wicks (Whatman \#1) and subjected to horizontal starch-gel electrophoresis (10.5\% w/v StarchArt, StarchArt Corp., Smithville, Texas) in an apparatus of "U-mold" design (Murphy et al., 1990 ) for 14-18 hr at $4 \mathrm{C}$. Homogenates representing 25 different individuals (including reference individuals of previously established genotype) were run on each gel. The following protein loci were surveyed for variability based on a previous study of midwestern and northeastern A. suum population samples (Leslie et al., 1982): isocitrate dehydrogenase (IDH, E.C. 1.1.1.42), phosphogluconate dehydrogenase (PGDH, E.C. 1.1.1.44), mannose-6-phosphate isomerase (MPI, E.C. 5.3.1.8), malate dehydrogenase (MDH, E.C. 1.1.1.37), malic enzyme (MDHP, E.C. 1.1.1.40), lactate dehydrogenase (LDH, E.C. 1.1.1.27), cytosol aminopeptidase (CAP, E.C. 3.4.11.1), L-leucyl-glycyl-glycine tripeptidase (PEP-B, E.C. 3.4.11.4), L-phenylalanyl-L-proline dipeptidase (PEP-D, E.C. 3.4.13.11), L-leucyl-L-alanine dipeptidase (LA-PEP, E.C. 3.4.13.11), 4-methyl-umbelliferyl acetate esterase (ESTD, E.C. 3.1.1.-), $\alpha$-naphthyl propionate esterase (EST, E.C. 3.1.1.-), and $\alpha$-naphthyl acetate esterase (EST, E.C. 3.1.1.-). Buffers used for electrophoresis included phosphatecitrate $\mathrm{pH} 6.8$ (electrode buffer $0.214 \mathrm{M}$ dibasic potassium phosphate, $0.027 \mathrm{M}$ citric acid; gel = 1:25 dilution of electrode buffer), Tris-maleateEDTA, pH 7.4 (electrode buffer $0.10 \mathrm{M}$ Trizma 7-9, $0.10 \mathrm{M}$ maleic acid, $0.01 \mathrm{M} \mathrm{MgCl}_{2}, 0.009 \mathrm{M}$ EDTA; gel = 1:9 dilution of electrode buffer), and continuous Tris-citrate II, pH 8.0 (Selander et al., 1971). Specific proteins were localized in gel slices using staining methods described in Murphy et al. (1990). Staining intensity of PEP-B was increased by wetting the surface of the gel slice with $0.1 \mathrm{M}$ Tris $(\mathrm{pH}$ 10.5 ), followed by incubation at room temperature for $5 \mathrm{~min}$ prior to staining. Phenotypic differences in isoenzyme banding patterns at a specific locus were used to deduce genotypes of individuals and the number of alleles segregating in the population samples. To confirm genotypic scores at the polymorphic loci, homogenates of every individual were electrophoresed and scored a minimum of 2 times along with appropriate reference individuals of established genotype. Four of the $100 \mathrm{~A}$. suum adults did not have sufficient gonadal tissue mass to prepare homogenates for isoenzyme analysis; these 4 individuals were excluded from all genetic analyses.

Individual nucleic acid isolations were prepared from 74 of the 96 individuals by homogenizing $0.15 \mathrm{~g}$ of muscle tissue with $500 \mu \mathrm{l}$ of STE buffer ( $10 \mathrm{mM}$ Tris- $\mathrm{HCl}, \mathrm{pH} 7.5,10 \mathrm{mM} \mathrm{NaCl}, 1 \mathrm{mM}$ EDTA) on ice, adding $100 \mu \mathrm{l}$ of $10 \%$ SDS (sodium dodecyl sulfate) and $20 \mu \mathrm{l}$ of proteinase $\mathrm{K}(10 \mathrm{mg} / \mathrm{ml})$, and incubating the homogenate at $50 \mathrm{C}$ for $1 \mathrm{hr}$. Tissue debris was removed by centrifugation and the supernatant extracted twice with buffered phenol (pH 8.0), and twice with chloroform/ isopentyl alcohol (24:1). Nucleic acids in the aqueous layer were precipitated with 2 volumes of $95 \%$ ethanol and $50 \mu \mathrm{l}$ of $3 \mathrm{M}$ sodium acetate (pH 5.2), washed once with $200 \mu \mathrm{l}$ ice-cold $70 \%$ ethanol, dried, and resuspended in $100 \mu \mathrm{l}$ of TE buffer ( $10 \mathrm{mM}$ Tris, $1 \mathrm{mM}$ EDTA, pH 8.0). The nucleic acid concentration of sample aliquots was estimated by spectrophotometry $\left(\mathrm{A}_{260} / \mathrm{A}_{280} / \mathrm{A}_{330}\right)$. Working template stocks of $75 \mathrm{ng} / \mu \mathrm{l}$ were prepared for each individual.

Twenty-nine different 10-mer primers of arbitrary (but known) nucleotide sequence (RAPD primer synthesis project, J. E. Carlson, University of British Columbia, Vancouver, British Columbia) were used to screen for polymorphic markers among individual $A$. suum. Initial experiments to optimize RAPD reaction conditions for $A$. suum nucleic acid templates involved empirical variation of annealing temperature and the concentrations of nucleic acid, $\mathrm{MgCl}_{2}$, dimethyl sulfoxide
(DMSO), primer, and Taq DNA polymerase. Optimal results were obtained by using $75 \mathrm{ng}$ of nucleic acid template in a solution consisting of $50 \mathrm{mM} \mathrm{KCl}, 10 \mathrm{mM}$ Tris- $\mathrm{HCl}, \mathrm{pH} 9.0,0.1 \%$ Triton X-100, $2 \mathrm{mM}$ $\mathrm{MgCl}_{2}, 5 \%$ (v/v) DMSO, $50 \mu \mathrm{M}$ each of dGTP, dATP, dTTP, dCTP, $0.2 \mu \mathrm{M}$ primer, and 1.2 units of $T a q$ DNA polymerase in a final reaction volume of $25 \mu \mathrm{l}$. Negative control (no nucleic acid) reactions were included for each primer. Double-distilled water used in these reactions was irradiated with $400 \mathrm{~mJ} / \mathrm{cm}^{2}$ of $254 \mathrm{~nm}$ light in an ultraviolet crosslinker to inactivate potential DNA contaminants (Sarkar and Sommer, 1990). Individual reaction mixtures were overlayed with $35 \mu \mathrm{l}$ of mineral oil (Sigma M-5904, Sigma Chemical, St. Louis, Missouri), and amplifications were performed in an MJ Research PTC 100-60 programmable thermal controller set to 45 cycles of $1 \mathrm{~min}$ at $94 \mathrm{C}, 1 \mathrm{~min}$ at $32 \mathrm{C}, 2$ min at $72 \mathrm{C}$, using the fastest rate of temperature transition. Amplification products and a 123-base pair (bp) ladder (size standard) were separated by electrophoresis in $1.2 \%$ agarose gels containing TBE buffer, pH 8.3 ( $89 \mathrm{mM}$ Tris, $89 \mathrm{mM}$ boric acid, $2 \mathrm{mM}$ EDTA), and nucleic acids were detected by staining with ethidium bromide $(0.5 \mu \mathrm{g} / \mathrm{ml})$ for $10 \mathrm{~min}$, and destaining in water for $25 \mathrm{~min}$. Ethidium-stained gels were photographed for subsequent scoring using ISO $3000 \mathrm{film}$. Each primer yielding a potentially scorable polymorphism was tested for reliability by repeating the reaction for approximately 20 individuals that displayed variation. Nine different RAPD primers yielding reliable, prominent, i.e., of intense fluorescence, and polymorphic amplification products were used for reactions in all 74 individuals. These primer codes (University of British Columbia numbers) and their sequences $\left(5^{\prime}-3^{\prime}\right)$ are: \#302 (CGGCCCACGT), \#306 (GTCCTCGTAG), \#308 (AGCGGCTAGG), \#314 (ACTTCCTCCA), \#316 (CCTCACCTGT), \#322 (GCCGCTACTA), \#337 (TCCCGAACCG), \#345 (GCGTGACCCG), and \#348 (CACGGCTGCG).

BIOSYS-1 (release 1.7, Swofford and Selander, 1981) was used to calculate isoenzyme allelic frequencies, determine the inbreeding coefficient $(F)$ for individual loci, and to test for conformance of genotype frequencies to Hardy-Weinberg equilibrium expectations. For the latter, chi-square tests with and without pooling of rare genotypes, and exact probability tests (Levene, 1949) were performed. $F$-statistics $\left(F_{I S}, F_{I T}\right.$, $F_{S T}$ ) were calculated according to the formulas of Nei and Chesser (1983) as modified by Van Den Bussche et al. (1986). These formulae incorporate corrections for the effects of small sample size on heterozygosity estimates. The modification by Van Den Bussche et al. (1986) also corrects for sampling errors within each individual subpopulation before estimating total gene diversity $\left(H_{T}\right)$. For the isoenzyme data, directcount heterozygosity and allelic frequencies from BIOSYS-1 were used to calculate $F$-statistics. Because the vast majority of segregating RAPD markers display a dominant mode of inheritance (Williams et al., 1990; Carlson et al., 1991; Welsh et al., 1991; Kazan et al., 1993; Kesseli et al., 1994), genotype and allelic frequencies within populations were calculated based on the observed frequency of the homozygous recessive condition ( $\mathbf{q}^{2}$, or marker absence), using the Hardy-Weinberg (diallelic) equation. Expected heterozygote and inferred allelic frequencies were used to calculate $F_{S T}$. Individual RAPD markers were excluded from the calculation of $F_{S T}$ when any population in the comparison had $\mathrm{q}^{2}$ $=0$, because with marker dominance and relatively small sample size, a value of $\mathrm{q}^{2}=0$ cannot be used to infer that $\mathrm{q}=0$. Mean $F_{S T}$ was calculated as $1-\Sigma H_{S} / \Sigma H_{T}$; average heterozygosity among subpopulations $\left(H_{S}\right)$ and total heterozygosity $\left(H_{T}\right)$ were determined according to the formulas of Van Den Bussche et al. (1986). Correlation between mean $F_{S T}$ values obtained by isoenzyme versus RAPD data was tested using 6 comparisons (Hinck versus Fult [Illinois]; Cas-1 versus Cas-2 [Michigan]; Bur-1 versus Bur-2 [Michigan]; Cas-1, Cas-2, Bur-1, Bur-2 [among Michigan]; pooled Cas-1 and Cas-2, pooled Bur-1 and Bur-2, Indian, Fult, Hinck [among geographic localities]; and among the 7 infrapopulations). To test for an association between genetic (isoenzyme) and geographic distance, a matrix of Rogers' (1972) genetic distance among populations was compared to a matrix of geographic distance among collection localities using Mantel's test of matrix correlation (Mantel, 1967; NTSYS-PC program) with 10,000 random permutations. For heuristic purposes, effective population size was estimated for the collected infrapopulations using the formula of Wright (1931). Although use of this formula entails many simplifying assumptions, more appropriate models of effective size, e.g., Chesser et al. (1993), require data that are currently unavailable for ascaridoid species. 
TABLE I. Isoenzyme allelic frequencies and sample sizes for Ascaris suum infrapopulations: $\mathrm{n}=$ sample size, $\mathrm{A}-\mathrm{F}=$ allele designations for each locus.

\begin{tabular}{cccccccc}
\hline & \multicolumn{7}{c}{ Population } \\
\cline { 2 - 8 } Locus & Fult & Hinck & Indian & Bur-1 & Bur-2 & Cas-1 & Cas-2 \\
\hline PEP-B & & & & & & & \\
n & 8 & 15 & 14 & 10 & 14 & 15 & 20 \\
A & 0.063 & & 0.036 & & & & \\
B & 0.375 & 0.267 & 0.071 & & 0.107 & 0.167 & 0.150 \\
C & 0.500 & 0.700 & 0.821 & 1.000 & 0.786 & 0.633 & 0.800 \\
D & & & & & 0.071 & & \\
E & 0.063 & 0.033 & 0.071 & & 0.036 & 0.167 & 0.050 \\
F & & & & & & 0.033 & \\
MPI & & & & & & & \\
n & 8 & 15 & 13 & 10 & 14 & 14 & 20 \\
A & 0.750 & 0.833 & 0.577 & 0.650 & 0.857 & 0.821 & 0.875 \\
B & 0.250 & 0.167 & 0.423 & 0.350 & 0.143 & 0.179 & 0.125 \\
PGDH & & & & & & & \\
n & 4 & 12 & 13 & 10 & 14 & 14 & 19 \\
A & & 0.125 & & 0.050 & 0.071 & 0.036 & \\
B & 0.125 & 0.375 & & 0.100 & 0.250 & 0.214 & 0.447 \\
C & & 0.083 & 0.154 & & 0.214 & 0.143 & 0.026 \\
D & 0.875 & 0.417 & 0.846 & 0.850 & 0.464 & 0.607 & 0.526 \\
\hline
\end{tabular}

\section{RESULTS}

\section{Isoenzyme data}

Six of the 13 loci surveyed showed evidence of polymorphism (MPI, PEP-B, PGDH, IDH, MDH, and ESTD); however, only 3 of the 6 variable loci (MPI, PEP-B, and PGDH) showed sufficient enzymatic activity and resolution on gels to score all individuals reliably (Table I). For these loci, homogenates of muscle gave the greatest relative staining activity for MPI and PEP-B; gonad had the best staining activity for PGDH. Optimal resolution of PGDH and MPI was obtained in the phosphatecitrate buffer; PEP-B resolution was best in the Tris-maleateEDTA buffer. Mannose-6-phosphate isomerase and PEP-B heterozygotes displayed banding patterns characteristic of monomeric subunit enzymes; the phenotype of PGDH heterozygotes was characteristic of a dimeric enzyme.

For the 7 infrapopulation samples from individual pigs, 3 included loci with statistically significant deviation from HardyWeinberg equilibrium expectations by both chi-square and exact probability tests $(P<0.05)$, and a fourth infrapopulation showed deviation by both types of chi-square testing (with and without pooling of rare genotypes). In 3 infrapopulations (Indian, Hinck, and Cas-1), PEP-B departed from equilibrium expectations; fixation indices at this locus in the respective populations were $F$ $=0.32, F=0.70$, and $F=0.63$. In 2 other infrapopulations (Indian and Cas-1), PGDH showed significant deviation from Hardy-Weinberg equilibrium expectations by both types of chisquare tests; fixation indices at this locus in the respective populations were $F=1.0$ and $F=0.49$. The Bur-1 infrapopulation also showed significant deviation from Hardy-Weinberg equilibrium expectations at the PGDH locus by both types of chisquare tests $(F=0.25)$. When Bur-1 and Bur-2 infrapopulations were pooled, PGDH showed significant departure from equilibrium expectations by all 3 statistical tests $(F=0.32)$. Likewise, analysis of pooled Cas-1 and Cas-2 infrapopulations also showed significant departure for PEP-B in chi-square tests with pooling $(F=0.34)$. Effective population numbers for the observed infrapopulations ranged from $N_{e}=3.6$ to $N_{e}=15$, (mean of 11.7). The overall sex ratio (male: female) of adults was $0.44: 1(n=$ 100); within individual infrapopulations it ranged from 0.1:1 to $1: 1$.

Mean inbreeding coefficients ( $F_{I S}$, Table II) were high among the 7 infrapopulations, the 5 pooled (by locality) populations, and between pairwise comparisons of infrapopulations, including those from single geographic localities. The mean fixation indices $\left(F_{S T}\right)$ for infrapopulations and localities (Table II) exceeded 0.05 in all but 1 case (the comparison of the Cas- 1 and Cas-2 infrapopulations from a single farm). For example, 9.4\% of the total allelic variance was distributed among infrapopulations and $90.6 \%$ was found within the infrapopulations. Likewise, $7.8 \%$ of the allelic variance was distributed among localities and $\mathbf{9 2 . 2 \%}$ within geographic regions. Alternatively, these $F$-statistics may be interpreted as the proportion of total variance or gene diversity found at a particular level. For example, $90.6 \%$ of the total estimated gene diversity was found within infrapopulations. Overall inbreeding coefficients (individual relative to the total population or $F_{I T}$ ) were high among infrapopulations and between localities (Table II); these $F$-statistics reflect reduction in heterozygosity due to nonrandom mating within subpopulations $\left(F_{I S}\right)$ plus that due to population subdivision $\left(F_{S T}\right)$. There was no significant correlation between Rogers' genetic distance (isoenzyme) and geographic distance for comparison of infrapopulations $(P=0.12)$ or the 5 pooled (by locality) populations $(P=0.11)$ as determined by Mantel's test; however, these results should be interpreted prudently given the relatively low statistical power of Mantel's test for small matrices.

TABLE II. Mean $F$-statistics among populations of Ascaris suum. Reported isoenzyme values are based on 3 loci. The number of RAPD markers used for the calculation of $F_{S T}$ is shown in parentheses.

\begin{tabular}{lcccccc}
\hline & $\begin{array}{c}7 \\
\text { Infrapopulations }\end{array}$ & $\begin{array}{c}5 \text { Geographic } \\
\text { locations }\end{array}$ & $\begin{array}{c}\text { 4 Michigan } \\
\text { infrapopulations }\end{array}$ & Cas-1 vs. Cas-2 & Bur-1 vs. Bur-2 & Hinck vs. Fult \\
\hline Isoenzyme $F_{I S}$ & 0.224 & 0.223 & 0.229 & 0.312 & 0.123 & 0.176 \\
Isoenzyme $F_{I T}$ & 0.295 & 0.283 & 0.282 & 0.328 & 0.194 & 0.227 \\
Isoenzyme $F_{S T}$ & 0.094 & 0.078 & 0.070 & 0.024 & 0.080 & 0.062 \\
RAPD $F_{S T}$ & $0.092(6)$ & $0.062(6)$ & $0.097(8)$ & $0.044(13)$ & $0.093(11)$ & $0.042(12)$ \\
\hline
\end{tabular}




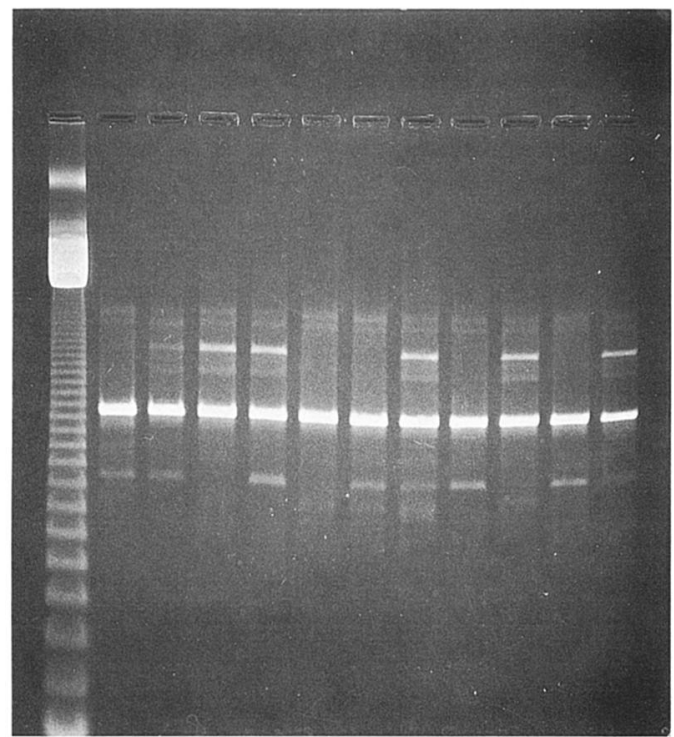

FIGURE 1. Random amplified polymorphic DNA fingerprints for 11 Ascaris suum individuals (primer \#302). From the left: lane 1, 123-bp size standard; lanes 2-12, individuals 400, 399, 397, 392, 387, 386, $384,383,382$, and 373 (see also Table III). The most prominent PCR product $(1,537 \mathrm{bp})$ was present in all individuals. Two other products $(1,046$ and $2,337 \mathrm{bp})$ were polymorphic. The 2,337-bp marker was present in individuals $399,397,392,385,383$, and 373 . Note that the 1,046-bp marker has a different pattern of variation and was present in individuals $400,399,392,386,385,384,382$, and 373 .

\section{RAPD data and comparative analysis of markers}

Of the 29 RAPD primers surveyed, 9 yielded amplification products that met both subjective (intense fluorescence) and objective (reproducibility) criteria for "scorability." These 9 primers yielded 25 scorable amplified products, e.g., Figure 1; 18 of these genetic markers were polymorphic (variable among individuals with respect to presence/absence) in the populations surveyed. The 25 scorable markers ranged in size from 277 to $2,337 \mathrm{bp}$ (Table III). Many amplified products of less than 500 bp were of poor reproducibility using these amplification conditions; products larger than $2.5 \mathrm{~kb}$ were rarely observed. Only fixation indices $\left(F_{S T}\right)$ were estimated for the RAPD data because their calculation does not depend directly on the frequency of observed heterozygotes (which cannot be scored directly with dominant markers). In 4 cases (primer 302/1,046 bp, 306/1,046, and $316 / 1,046 ; 308 / 738$ and $322 / 738 ; 308 / 923$ and $337 / 923$; $314 / 861$ and $345 / 861$ ), primers of different nucleotide sequence yielded amplification profiles with at least 1 marker of approximately the same size as estimated from agarose gels; however, patterns of marker presence/absence within the $A$. suum individuals were distinctly different in each of these cases (Table III). In addition, side-by-side comparisons of these products revealed minor differences in electrophoretic mobility in all cases (not shown). The number of RAPD markers used to calculate mean $F_{S T}$ ranged from 6 to 13 (Table II), depending on the number of markers excluded due to $\mathrm{q}^{2}=0$ values in the comparison. Independent estimates of $F_{S T}$ by RAPD and isoenzyme methods yielded similar levels of differentiation in several cases (Table II), including the overall differentiation among the 7 infrapopulations (isoenzyme $F_{S T}=0.094$; RAPD $F_{S T}=0.092$ ).
Notable was the low level of infrapopulation differentiation $\left(F_{S T}\right.$ $<0.05$ ) between Cas-1 and Cas-2 (same farm) infrapopulations as revealed by both isoenzyme and RAPD data, and the moderate level of differentiation between the Bur-1 and Bur-2 (different farm) infrapopulations (isoenzyme $F_{S T}=0.08$; RAPD $F_{S T}=0.093$ ). Mean $F_{S T}$ values derived from isoenzyme versus RAPD markers ( 6 comparisons) had a correlation coefficient of 0.70 . Coefficients of variation for mean $F_{S T}$ values, were, on average, 1.8 times greater for RAPD than isoenzyme markers.

\section{DISCUSSION}

Relatively few studies have focused on the genetics of geographic variation among populations of parasite helminths. In part, this is due to the limited usefulness of traditional approaches, i.e., protein electrophoresis, for obtaining multilocus genetic data from small individual organisms. Clearly, techniques that allow for the direct determination of single individual genotypes are methods of choice; however, RAPD-based studies are beginning to receive more widespread use in parasitology due to their relatively low cost and applicability to small organisms (Bandi et al., 1993; Roosien et al., 1993; Gardner et al., 1994). Breeding studies of plants and fungi have demonstrated that most polymorphic RAPDs have a Mendelian pattern of inheritance (Williams et al., 1990; Kazan et al., 1993; Kesseli et al., 1994); these studies have also revealed that patterns of expression of RAPD markers are consistent with dominance in greater than $90 \%$ of approximately 200 segregating markers examined. Unfortunately, properties of population structure such as levels of inbreeding within subpopulations cannot be readily assessed with dominant markers. Thus, although this comparative study demonstrated that RAPDs can be used for estimating differentiation among parasite populations, these markers cannot be used to quantify patterns of nonrandom mating within subpopulations as evidenced by the isoenzyme data.

Given the difficulty of performing experimental crosses for most parasites, the reliability of particular RAPD reaction products for subsequent analysis must be based on other criteria such as repeatability and band intensity. For $A$. suum, approximately one-third of the 10 -mer primers screened yielded 1 or more amplification products meeting these criteria, and approximately two-thirds of the reliable markers were polymorphic. Reaction products smaller than 500 bp were typically of limited usefulness due to poor reliability; products larger than $2.5 \mathrm{~kb}$ were rarely observed, presumably because the extension time of each PCR cycle was limited to $2 \mathrm{~min}$. In several cases, primers of distinct nucleotide sequence yielded RAPD reaction products of approximately the same size as estimated from comparison to a molecular weight ladder in agarose mini-gels. Greater electrophoretic resolution and more precise estimates of size would be obtained by using polyacrylamide electrophoresis (Hadrys et al., 1992); however, the independence of these similar-size markers was established by different patterns of variation in the same individual nematodes. Estimating allele and genotype frequencies for RAPD markers was compromised when the recessive genotype was absent from a particular population. In this study, RAPD markers were excluded from calculation of the fixation index whenever any of the subpopulations in a particular comparison had a frequency of zero for the recessive 
genotype. Thus, although 18 polymorphic markers were detected in these midwestern population samples of $A$. suum, calculations of fixation indices were based on 6-13 markers, depending on the subpopulations compared. Because of this limitation, population-level studies that focus on polymorphic RAPD markers may require the use of many different individual primers. Alternatively, an unbiased survey of RAPD primers could be used to estimate nucleotide divergence among populations when certain stringent criteria are satisfied (Clark and Lanigan, 1993).

Independent estimates of fixation indices based on isoenzyme and RAPD markers showed the same general patterns of differentiation. The correlation analysis demonstrated a substantial relationship between these estimates of differentiation; however, estimates of the mean fixation index based on RAPD markers had almost twice the coefficient of variation than those based on isoenzyme markers. In part, this difference must be due to errors caused by estimating allele and genotype frequencies from the observed frequency of a single genotypic class (homozygous recessives) when sample size was small. It is also possible that levels of functional constraint (and selective neutrality) may be more variable for RAPD markers in comparison to isoenzyme loci. Regardless of cause, this result suggests that fixation indices calculated from few polymorphic RAPD markers should be interpreted cautiously.

A paradigm of parasite population structure is that parasitic organisms are characterized by small populations with high levels of inbreeding, low intrapopulation genetic variability, i.e., polymorphism, heterozygosity, and allelism, and high levels of interpopulation differentiation due to genetic drift and founder effects (Price, 1980). Parasite populations are expected to be in a nonequilibrium state due to patch dynamics (Price, 1980), and infrapopulations are believed to be reconstituted in each generation of hosts by random immigration from the larger gene pool of parasite life cycle stages (Brooks and McLennan, 1993). Reported levels of interpopulation differentiation (subdivision) for parasites show a wide range of values (Lydeard et al., 1989; Nadler, 1990; Barker et al., 1991; Mulvey et al., 1991; Blouin et al., 1992; Dame et al., 1993), at least some of which may be explained by the geographic scale of investigation (Mulvey et al., 1991) and the natural history of the host-parasite system. Although some parasite populations have been reported to have low intrapopulation variability (Bull et al., 1984; Bullini et al., 1986; Barker et al., 1991), low genetic variability does not appear to be a general feature of parasite populations based on studies of mtDNA or nuclear-encoded isoenzyme loci (Nadler, 1990; Paggi et al., 1991; Blouin et al., 1992; Anderson et al., 1993; Dame et al., 1993). However, few studies have attempted to use allelic frequency data to quantify intrapopulation and interpopulation differentiation; instead, most inferences concerning population structure have been based on the long-term consequences of inbreeding, i.e., reduced genetic variability.

The effects of inbreeding can be quantified by $F$-statistics with respect to different reference populations (Wright, 1922, 1965). The inbreeding coefficient $\left(F_{I S}\right)$ describes the reduction in heterozygosity of an individual within its subpopulation compared to that expected in a randomly mating population with the same allelic frequencies. The reduction in heterozygosity of a subpopulation due to genetic drift is referred to as the fixation index $\left(F_{S T}\right)$. The overall inbreeding coefficient of an individual $\left(F_{I T}\right)$ reflects the reduction of heterozygosity due to nonrandom mating within subpopulations $\left(F_{I S}\right)$ and that due to population subdivision $\left(F_{S T}\right)$. Alternatively, $F$-statistics may be interpreted as the probability of autozygosity or identity of alleles by descent (Wright, 1965). $F$-statistics calculated from genetic data are frequently used to estimate levels of gene flow among demes; however, these estimates are dependent upon a specified model of population structure and the assumption that observed allelic frequencies have reached an equilibrium between gene flow and genetic drift. Gene flow estimates were not calculated for these data because for organisms with ephemeral demes (presumably many parasites), frequent extinction and recolonization will generally lead to overestimates of gene flow using standard island models of population structure (Slatkin, 1985; Preziosi and Fairbairn, 1992).

These isoenzyme data revealed excess homozygosity as indicated by high inbreeding coefficients for infrapopulations of A. suum. Within individual infrapopulations, protein loci departing from Hardy-Weinberg equilibrium expectations in statistical tests showed a pronounced deficiency of heterozygotes. These deficits cannot be attributed to problems associated with scoring heterozygotes because the loci selected for study were clearly resolved for each individual. Analysis of pooled infrapopulations from individual geographic regions (Cas-1 and Cas2; Bur-1 and Bur-2) revealed that loci departing from equilibrium expectations within the respective infrapopulations (Cas1, Bur-1) also showed heterozygote deficiencies in the pooled samples. However, interpretation of inbreeding for pooled population samples is more complex because heterozygote deficiencies may result from pooling distinct subpopulations with different allelic frequencies, i.e., a Wahlund effect (Wahlund, 1929). Thus, a Wahlund effect may account for some of the heterozygote deficiency in the pooled Bur samples (infrapopulations from different farms) where allelic frequencies at the PGDH locus were markedly different. A Wahlund effect has been observed previously for other pooled population samples of ascaridoid species (Nadler, 1986) and other parasites (Lydeard et al., 1989). A Wahlund-like effect might also explain departures from equilibrium expectations within individual infrapopulations if such populations sometimes result from multiple infections, each of distinct origin.

Departures from random mating were also indicated by high positive values of $F_{I S}$ among and between infrapopulations. Among all 7 infrapopulations, the average inbreeding coefficient was 0.22 . The highest value of $F_{I S}$ was observed for the comparison of 2 infrapopulations from a single farm (Cas). All $F_{I S}$ values obtained in this study were very high when compared to reported values for other parasites and free-living organisms. For example, the average inbreeding coefficient (among infrapopulations or geographic localities) for midwestern A. suum is roughly an order of magnitude greater than that reported by Mulvey et al. (1991) for geographic populations (=Savannah River Site hunt units) of the fluke (Fascioloides magna) that were characterized as inbred. Comparisons of populations of this same fluke from 4 localities in the southeastern United States (Lydeard et al., 1989) also revealed a smaller inbreeding coefficient (mean $F_{I S}=0.08$ ) than observed for $A$. suum. Likewise, levels of inbreeding found in $A$. suum were markedly greater than that reported for 23 infrapopulations of ectoparasitic chewing lice (average $F_{I S}=0.069$ ) along a $200-\mathrm{km}$ contact zone 


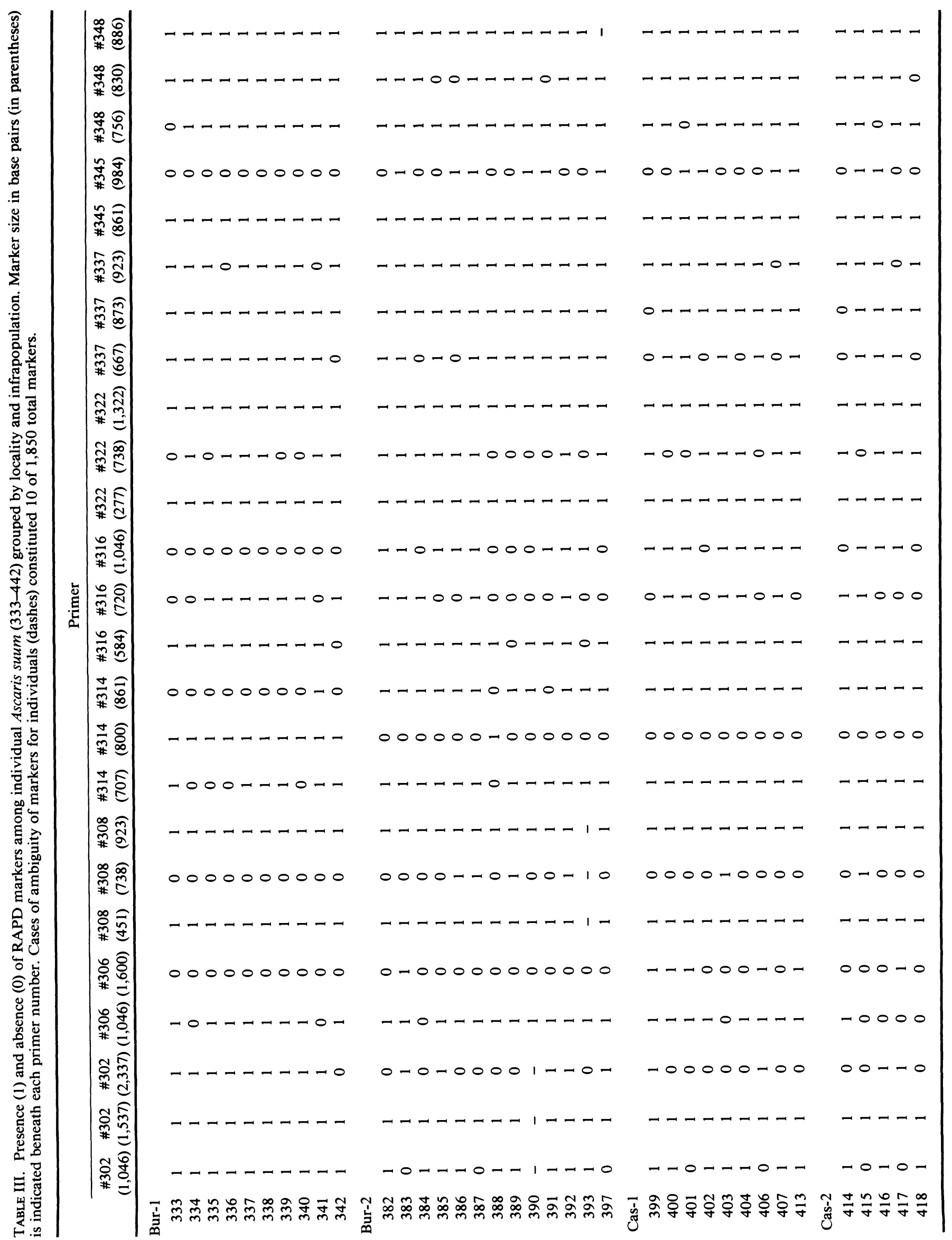




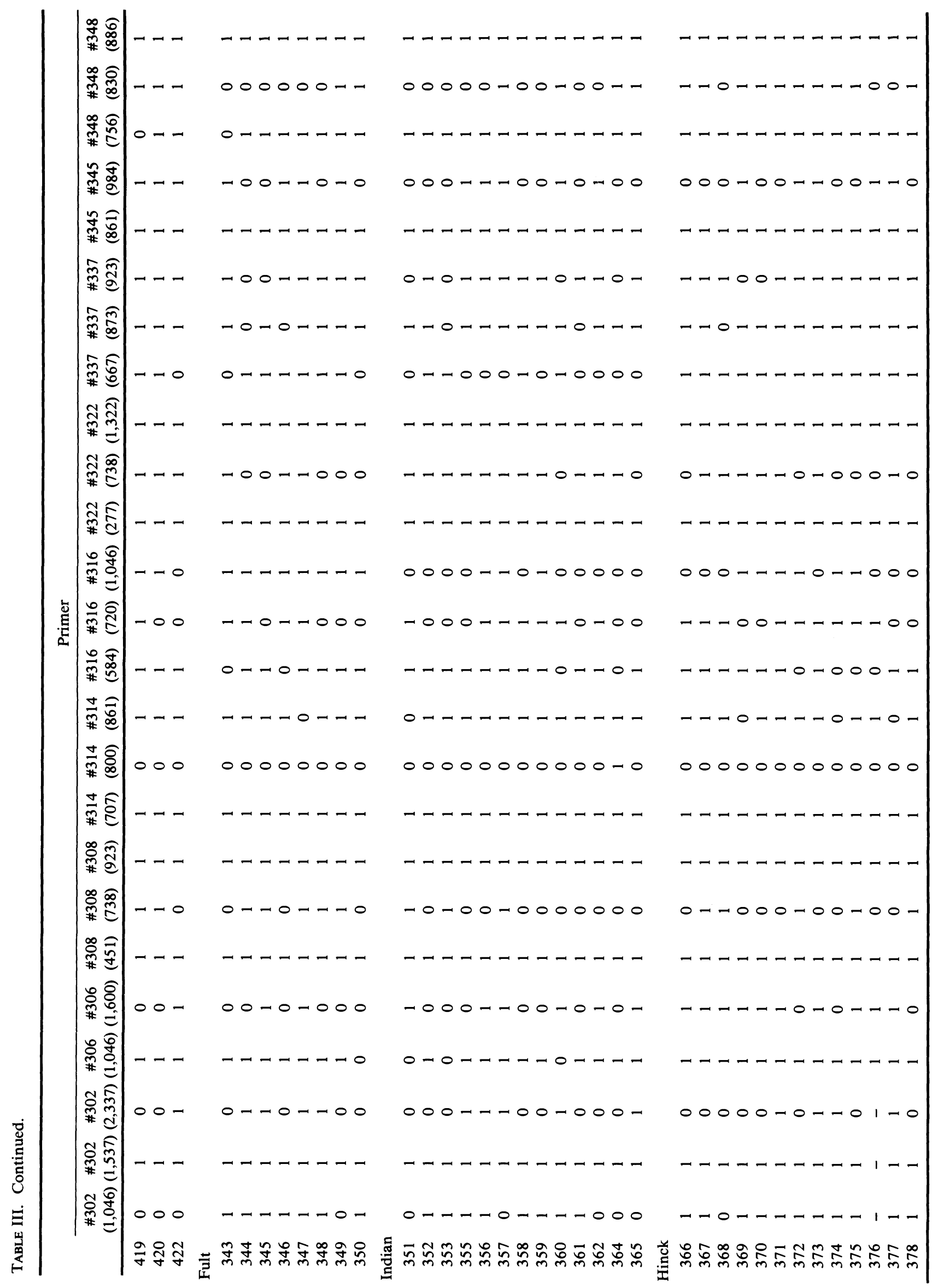


of their pocket gopher hosts (Nadler et al., 1990). Thus, the genetic composition of these $A$. suum infrapopulations, whether from a general geographic region or a single farm, is not consistent with a model of random recruitment from a larger panmictic pool of parasite life cycle stages. Because sexual reproduction of $A$. suum occurs within individual pig hosts, inbreeding may be promoted if sib-sib or parent-offspring matings occur with a greater than expected frequency. The likelihood of sibsib matings would be enhanced if infrapopulations were frequently established from clusters of infective eggs that themselves represent kindred individuals, i.e., eggs resulting from a single mating or from matings between close relatives, rather than eggs representing a random sample of the available genotypes. Because Ascaris generations are overlapping, parentoffspring matings may also contribute to the observed $F_{I S}$ values, given that the host humoral immune response in Ascaris infections reflects recent exposure to migrating larvae (Bundy and Medley, 1992; Haswell-Elkins et al., 1992) and does not appear to be protective.

The potential fitness consequences of the inferred level of inbreeding in $A$. suum merits additional investigation. Experimental studies on nonparasitic organisms have demonstrated a substantial reduction in fitness associated with inbreeding (inbreeding depression), which is believed to result from an increased frequency of deleterious recessive alleles (Simmons and Crow, 1977; Charlesworth and Charlesworth, 1987; Willis, 1993). However, inbreeding can also preserve favorable coadapted gene complexes or epistatic interactions (Templeton, 1987; Lynch, 1991), which may be important for host-parasite coadaptation (Price, 1980). It is tempting to speculate that underlying variation in host innate resistance to different inbred lines of parasites in combination with heterogeneity in acquired resistance, e.g., Tanguay and Scott (1992) may account for some of the overdispersion characteristic of many parasites in general (Anderson and May, 1978) and for Ascaris infections in particular.

The amount of inbreeding in $A$. suum due to population subdivision (mean fixation index or $F_{S T}$ ) for infrapopulations and localities, as inferred by both isoenzyme and RAPD markers, is characteristic of moderate genetic differentiation (Hartl, 1988). For example, $90.6 \%$ (isoenzyme) and $90.8 \%$ (RAPD) of the total estimated gene diversity was found within infrapopulations, i.e., approximately $9 \%$ was partitioned among infrapopulations. When infrapopulations from single geographic regions were pooled, $92.2 \%$ (isoenzyme) and $93.8 \%$ (RAPD) of the total gene diversity was found within regions. Only infrapopulations from a single farm (Cassopolis) were characterized by low fixation indices. Conversely, 2 infrapopulations representing different farms from a single geographic region (Burlington) showed moderate genetic differentiation, with $92 \%$ (isoenzyme) and $90.7 \%$ (RAPD) of the gene diversity at this locality distributed within the infrapopulations. Similarly, comparisons of infrapopulations collected within southern Michigan revealed differentiation of the same magnitude as found for the comparison of all midwestern infrapopulations. These results indicate significant genetic isolation among farms within geographic regions and suggest that only hosts at a farm have sufficient exchange of Ascaris eggs to reduce the effects of differentiation by genetic drift.

In species where demes are continuously distributed over geographic space, the isolation-by-distance model (Crow and $\mathrm{Ki}$ - mura, 1970) predicts a correlation between geographic and genetic distance among demes as a result of genetic drift. For species with highly subdivided populations, this correlation is also expected if gene flow among the populations is proportional to geographic distance. The absence of a correlation between genetic (isoenzyme) and geographic distance for these $A$. suum infrapopulations (and for localities) is suggestive of low gene flow between closest populations at the geographic scale examined and reinforces the conclusion that there is genetic isolation among these infrapopulations. These results are inconsistent with the preliminary studies of Leslie et al. (1982), who inferred low differentiation between $A$. suum samples from midwestern (Iowa) and eastern (New Jersey) localities based on the observation that allelic frequencies for 3 isoenzyme loci were generally similar between these samples. Unfortunately, the results of Leslie et al. (1982) cannot be compared directly to the results of the current study because in their work, worms were assigned to geographic areas, e.g., eastern Iowa, New Jersey, but not to individual pig hosts or specific farms. Furthermore, the absence of reported genotype frequencies and sample sizes precludes recalculating $F$-statistics from their data. By contrast, a recent study of pig-source Ascaris representing 2 geographic regions of Guatemala also revealed statistically significant differences in allelic frequencies at 2 isoenzyme loci (Anderson et al., 1993).

Genetic drift among $A$. suum infrapopulations may be promoted by their small effective population size and founder effects. The overall sex ratio (male: female) of adults was $0.44: 1$, which is consistent with the range of values reported for the human ascaridoid Ascaris lumbricoides (Guyatt and Bundy, 1993). This skewed sex-ratio (female bias) significantly reduced the effective population size $\left(N_{e}\right)$ below the census size, because in each generation half of the alleles in offspring must come from males. The mean estimated $N_{e}$ for these infrapopulations was very small, and the cumulative effect of random genetic drift in populations of this (and somewhat larger) size may lead to significant changes in allelic frequency over relatively few generations ( $\mathrm{Li}$ and Graur, 1991). Small effective population size may also be responsible for the relatively low levels of isoenzyme heterozygosity reported for certain population samples of $A$. suum (Bullini et al., 1986; Anderson et al., 1993).

In contrast to the low effective population size inferred for $A$. suum, free-living nematodes and other parasitic species may be characterized by much larger $N_{e}$. For example, in a study of Ostertagia ostertagi, Blouin et al. (1992) calculated a long-term $N_{e}$ (=the harmonic mean of $N_{e}$ for past years) of 4-8 million individuals per geographic population based on the observed diversity of mtDNA within populations. The large effective size of $O$. ostertagi populations is also supported by studies of infrapopulations; individual hosts may harbor 10,000-100,000 worms at 1 time (Armour, 1978; Williams et al., 1983) and the adult sex ratio is approximately $1: 1$ (Triantaphylou, 1983). Importantly, population-genetic studies of mtDNA in $O$. ostertagi (Blouin et al., 1992; Dame et al., 1993) have shown very high intrapopulation genetic diversity and extremely low interpopulation differentiation, with less than $1 \%$ of the total gene diversity partitioned among geographic populations. For $O$. ostertagi, gene flow among localities appears to be high (Blouin et al., 1992), or cessation of gene flow recent. By contrast, once the effects of haplotype introgression were removed, Anderson 
et al. (1993) reported 10-fold lower levels of mtDNA diversity within "population clusters" of Ascaris. Thus, these preliminary studies are consistent with the expectation that effective population size may impact on intrapopulation diversity, and that helminth species with large $N_{e}$ may show minimal differentiation due to genetic drift.

The potential importance of geographic scale in relation to neighborhood size remains an important consideration for future studies of parasite population structure. In natural populations, scale effects have been studied in flukes (Fascioloides magna) from white-tailed deer (Lydeard et al., 1989; Mulvey et al., 1991); populations of flukes from the Savannah River Site showed low differentiation (mean $F_{S T}=0.016$ ), whereas comparison of populations from different states (South Carolina and Tennessee) showed high levels of differentiation (mean $F_{S T}$ $=0.18$ ) and an isolation-by-distance effect. In another study relating to scale, within-locality infrapopulation differentiation for lice (Geomydoecus actuosi) from pocket gopher hosts was high (mean $F_{S T}=0.092$ ), thus reinforcing the model that these rodent hosts represent an island-like distribution of habitat for these contact-transmitted ectoparasites (Nadler et al., 1990). In the same study, macrogeographic infrapopulation differentiation (over a $200-\mathrm{km}$ transect) for lice was much greater $\left(F_{S T}=\right.$ $0.24)$ and virtually identical to the genetic differentiation observed for their hosts, suggesting a close association between gene flow for the hosts and their ectoparasites. Obviously, the intrinsic vagility of parasites in combination with host mobility will interact to influence the genetic differentiation of parasites over geographic space. However, beyond "simple" systems of one-host contact-transmitted parasites, e.g., pocket gophers and lice, modeling and interpreting the genetics of geographic variation in natural populations may be complicated by asexual amplification within intermediate hosts, e.g., digenetic trematodes (Lydeard et al., 1989; Mulvey et al., 1991), the population structure and dynamics of obligate intermediate and paratenic hosts (Price, 1980), and the persistence of larval stages in the environment. For domesticated animals, the transport of livestock and their parasites will further complicate interpretation of population structure, particularly since such movements are not likely to be uniform over space or time. However, given the results of this and other initial studies (Blouin et al., 1992; Dame et al., 1993), different helminth parasites of domesticated animals may have distinct patterns of genetic structure, at least some of which may be attributable to differences in effective population size of the parasites.

\section{ACKNOWLEDGMENTS}

We are grateful to Mr. Don Temperly for assistance at FDL in obtaining specimens. We thank Rita Highland, Chris Lin, Davida Alexander, Steve Muszynski, and Kevin Beitz for laboratory help. We are also grateful to Dr. Richard King and Jim Demastes for assistance with data analysis. This research was supported by BRSG S07RR07176\#112, and by the National Institute of Allergy and Infectious Diseases (AI 34151-01).

\section{LITERATURE CITED}

ANDERSON, R. M., AND R. M. MAY. 1978. Regulation and stability of host-parasite population interactions. I. Regulatory process. Journal of Animal Ecology 47: 219-247.
Anderson, T. J. C., M. E. Romero-Abal, AND J. Jaenike. 1993. Genetic structure and epidemiology of Ascaris populations: Patterns of host affiliation in Guatemala. Parasitology 107: 319-334.

Armour, J. 1978. Arrested development in cattle nematodes with special reference to Ostertagia ostertagi. In Facts and reflections III. Workshop on arrested development of nematodes in sheep and cattle, F. H. M. Borgsteede, J. Armour, and J. Jansen (eds.). Central Veterinary Institute, Lelystad, The Netherlands, p. 77-88.

Arnold, M. L., C. M. Buckner, AND J. J. Robinson. 1991. Pollenmediated introgression and hybrid speciation in Louisiana irises. Proceedings of the National Academy of Sciences USA 88: 13981402.

Bandi, C., G. La Rosa, S. Comincini, G. Damiani, and E. Pozio. 1993. Random amplified polymorphic DNA technique for the identification of Trichinella species. Parasitology 107: 419-424.

Barker, S. C., D. A. Briscoe, R. L. Close, and P. Dallas. 1991. Genetic variation in the Heterodoxus octoseriatus group (Phthiraptera): A test of Price's model of parasite evolution. International Journal for Parasitology 21: 555-563.

Blouin, M. S., J. B. Dame, C. A. Tarrant, and C. H. Courtney. 1992. Unusual population genetics of a parasitic nematode: mtDNA variation within and among populations. Evolution 46: 470-476.

Brooks, D. R., AND D. A. McLenNaN. 1993. Parascript. Smithsonian Institution Press, Washington, D.C., 429 p.

Bull, C. M., R. H. ANDREws, AND M. AdAMS. 1984. Patterns of genetic variation in a group of parasites, the Australian reptile ticks. Heredity 53: 509-525.

Bullini, L., G. Nascetti, L. Paggi, P. Orecchia, S. Mattiucci, and B. BERLAND. 1986. Genetic variation of ascaridoid worms with different life cycles. Evolution 40: 437-440.

Bundy, D. A. P., AND G. F. MEDley. 1992. Immuno-epidemiology of human geohelminthiasis: Ecological and immunological determinants of worm burden. Parasitology 104(supplement): 105-119.

Carlson, J. E., J. K. Tulsieram, J. C. Glaubitz, V. W. K. Luk, C. KAUFFELd, AND R. RUTLEDGE. 1991. Segregation of random amplified DNA markers in F1 progeny of conifers. Theoretical and Applied Genetics 83: 194-200.

Charlesworth, D., AND B. Charlesworth. 1987. Inbreeding depression and its evolutionary consequences. Annual Review of Ecology and Systematics 18: 237-268.

Chesser, R. K., O. E. Rhodes Jr., D. W. Sugg, and A. Schnabel. 1993. Effective sizes for subdivided populations. Genetics 135: 1221-1232.

Clark, A. G., and C. M. S. Lanigan. 1993. Prospects for estimating nucleotide divergence with RAPDs. Molecular Biology and Evolution 10: 1096-1111.

Crow, J. F., AND M. Kimura. 1970. An introduction to population genetics theory, 1 st ed. Harper and Row, New York, $591 \mathrm{p}$.

Dame, J. B., M. S. Blouin, AND C. H. Courtney. 1993. Genetic structure of populations of Ostertagia ostertagi. Veterinary Parasitology 46: 55-62.

Gardner, S. L., P. Stock, AND H. K. Kaya. 1994. A new species of Heterorhabditis from the Hawaiian islands. Journal of Parasitology 80: 100-106.

GuYATT, H. L., AND D. A. P. Bundy. 1993. Estimation of intestinal nematode prevalence: Influence of parasite mating patterns. Parasitology 107: 99-105.

HADRYS, H. 1991. Postkopulatorische mannchenkonkurrenz und RAPD fingerprinting in odonaten. Verhandlungen der Deutschen Zoologischen Gesellschaft 84: 306-307.

HADRYS, H., M. BALICK, AND B. SCHIERWATER. 1992. Applications of random amplified polymorphic DNA (RAPD) in molecular ecology. Molecular Ecology 1: 55-63.

HARTL, D. 1988. A primer of population genetics, 2nd ed. Sinauer Associates, Sunderland, Massachusetts, 305 p.

Haswell-Elkins, M. R., H. Leonard, M. W. Kennedy, D. B. Elkins, AND R. M. MAIZELS. 1992. Immunoepidemiology of Ascaris lumbricoides: Relationships between antibody specificities, exposure and infection in a human community. Parasitology 104: 153-159.

Kazan, K., J. M. ManNers, and D. F. Cameron. 1993. Inheritance of random amplified polymorphic DNA markers in an interspecific cross in the genus Stylosanthes. Genome 36: 50-56.

Kesseli, R. V., I. Paran, AND R. W. Michelmore. 1994. Analysis of 
a detailed genetic linkage map of Lactuca sativa (lettuce) constructed from RFLP and RAPD markers. Genetics 136: 1435-1446.

Leslie, J. F., G. D. Cain, G. K. Meffe, and R. C. Vruenhoek. 1982. Enzyme polymorphism in Ascaris suum (Nematoda). Journal of Parasitology 68: 576-587.

LEVENE, H. 1949. On a matching problem arising in genetics. Annals of Mathematical Statistics 20: 91-94.

Li, W.-H., AND D. GRAUR. 1991. Fundamentals of molecular evolution, 1st ed. Sinauer Associates, Sunderland, Massachusetts, 284 p.

Lydeard, C., M. Mulvey, J. M. Aho, and P. K. Kennedy. 1989. Genetic variability among natural populations of the liver fluke, Fascioloides magna, in white-tailed deer, Odocoileus virginianus. Canadian Journal of Zoology 67: 2021-2025.

LYNCH, M. 1991. The genetic interpretation of inbreeding depression and outbreeding depression. Evolution 45: 622-629.

MANTEL, N. 1967. The detection of disease clustering and a generalized regression approach. Cancer Research 27: 209-220.

Margolis, L., G. W. Esch, J. C. Holmes, A. M. Kuris, and G. A. SCHAD. 1982. The use of ecological terms in parasitology (Report of an ad hoc committee of the American Society of Parasitologists). Journal of Parasitology 68: 131-133.

Martin, G. B., J. G. K. Williams, AND S. D. Tanksley. 1991. Rapid identification of markers linked to a Pseudomonas resistance gene in tomato by using random primers and near-isogenic lines. Proceedings of the National Academy of Sciences USA 88: 2336-2340.

Mulvey, M., J. M. AHo, C. LydeARd, P. L. Leberg, AND M. H. Smith. 1991. Comparative population genetic structure of a parasite (Fascioloides magna) and its definitive host. Evolution 45: 1628-1640.

Murphy, R. W., J. W. Sites, JR., D. G. Buth, and C. H. Haufler. 1990. Proteins I: Isozyme electrophoresis. In Molecular Systematics, D. M. Hillis and C. Moritz (eds.). Sinauer Associates, Sunderland, Massachusetts, p. 45-126.

NADLER, S. A. 1986. Biochemical polymorphism in Parascaris equorum, Toxocara canis and Toxocara cati. Molecular and Biochemical Parasitology 18: 45-54.

- 1990. Molecular approaches to studying helminth population genetics and phylogeny. International Journal for Parasitology 20: 11-29.

- M. S. HAFNer, J. C. HAFNer, AND D. J. HAFNer. 1990. Genetic differentiation among chewing louse populations (Mallophaga: Trichodectidae) in a pocket gopher contact zone (Rodentia: Geomyidae). Evolution 44: 942-951.

NeI, M., AND R. K. Chesser. 1983. Estimation of fixation indices and gene diversities. Annals of Human Genetics 47: 253-259.

Paggi, L., G. Nascetti, R. Cianchi, P. Orecchia, S. Mattiucci, S. D'Amelio, B. Berland, J. Brattey, J. W. Smith, and L. Bullini. 1991. Genetic evidence for three species within Pseudoterranova decipiens (Nematoda Ascaridida, Ascaridoidea) in the north Atlantic and Norwegian and Barents seas. International Journal for Parasitology 21: 195-212.

Preziosi, R. F., AND D. J. FAIRBAiRn. 1992. Genetic population structure and levels of gene flow in the stream dwelling waterstrider, Aquarius (=Gerris) remigis (Hemiptera: Gerridae). Evolution 46: $430-444$.

PRICE, P. W. 1980. Evolutionary biology of parasites. Princeton University Press, Princeton, New Jersey, 237 p.

ROGERS, J.S. 1972. Measures of genetic similarity and genetic distance. In Studies in genetics VII, University of Texas publication 7213 , p. $145-153$.

Roosien, J., P. M. Van Zandvoort, R. T. Foklertsma, J. N. A. M. Rouppe Vand Der Voort, A. Goverse, F. J. Gommers, AND J. BAKKER. 1993. Single juveniles of the potato cyst nematodes Glo- bodera rostochiensis and G. pallida differentiated by randomly amplified polymorphic DNA. Parasitology 107: 567-572.

SARKAR, G., AND S. S. Sommer. 1990. Shedding light on PCR contamination. Nature 343: 27

Selander, R. K., M. H. Smith, S. Y. Yang, W. E. Johnson, and J. B. GENTRY. 1971. Biochemical polymorphism and systematics in the genus Peromyscus. I. Variation in the old field mouse (Peromyscus polionotus). In Studies in genetics VI, University of Texas publication 7103, p. 49-90.

Simmons, M. J., AND J. F. CROw. 1977. Mutations affecting fitness in Drosophila populations. Annual Review of Genetics 11: 49-78.

SlATKIN, M. 1985. Rare alleles as indicators of gene flow. Evolution 39: 53-65.

Smith, M. L., J. N. Bruhn, AND J. B. ANDerson. 1992. The fungus Armillaria bulbosa is among the largest and oldest living organisms. Nature 356: 428-431.

SwoFford, D. L., AND R. B. SElANDER. 1981. BIOSYS-1: A Fortran program for the comprehensive analysis of electrophoretic data in population genetics and systematics. Journal of Heredity 72: 281283.

TANGUAY, G. V., AND M. E. ScOTt. 1992. Factors generating aggregation of Heligmosomoides polygyrus (Nematoda) in laboratory mice. Parasitology 104: 519-529.

Tarrant, C. A., M. S. Blouin, C. A. Yowell, AND J. B. Dame. 1992. Suitability of mitochondrial DNA for assaying interindividual genetic variation in small helminths. Journal of Parasitology 78: 374 378.

TEMPLETON, A. R. 1987. Inferences on natural population structure from genetic studies on captive mammalian populations. In Mammalian dispersal patterns, B. D. Chepko-Sade and Z. T. Halpin (eds.). University of Chicago Press, Chicago, Illinois, p. 257-272.

TriantaPhylou, A. C. 1983. Cytogenetic aspects of nematode evolution. In Concepts in nematode systematics, A. R. Stone, H. M. Platt, and L. F. Khalil (eds.). Academic Press, New York, p. 2540.

Van Den Bussche, R. A., M. J. Hamilton, AND R. K. Chesser. 1986. Problems of estimating gene diversity among populations. Texas Journal of Science 38: 281-287.

WAHLUND, S. 1929. Zusammensetzung von populationen und korrelationserscheinungen vom standpunkt der verebungslehre aus betrachtet. Hereditas 11: 65-106.

Welsh, J., C. Petersen, ANd M. MCClelland. 1991. Polymorphisms generated by arbitrarily primed PCR in the mouse: Application to strain identification and genetic mapping. Nucleic Acids Research 20: 303-306.

Williams, J. C., J. W. Knox, B. A. Baumann, T. G. Snider, M. G. Kimball, AND T. J. HoERNER. 1983. Seasonal changes of gastrointestinal nematode populations in yearling beef cattle in Louisiana with emphasis on prevalence of inhibition in Ostertagia ostertagi. International Journal for Parasitology 13: 133-143.

Williams, J. G. K., A. R. Kubelik, K. J. Livak, J. A. Rafalski, and S. V. TINGEY. 1990. DNA polymorphisms amplified by arbitrary primers are useful as genetic markers. Nucleic Acids Research 18: $6531-6535$.

WiLLIS, J. H. 1993. Effects of different levels of inbreeding on fitness components in Mimulus guttatus. Evolution 47: 864-876.

WRIGHT, S. 1922. Coefficients of inbreeding and relationship. American Naturalist 56: 330-338.

- 1931. Evolution in Mendelian populations. Genetics 16: 97159.

1965. The interpretation of population structure by $F$-statistics with special regard to systems of mating. Evolution 19: 395-420. 